\title{
An outbreak of cryptosporidiosis in a hospital day-care centre
}

\author{
BY J. A. G. MELO CRISTINO, M. ISABEL P. CARVALHO AND MARIA \\ JOSÉ SALGADO
}

Laboratório de Bacteriologia, Hospital de Santa Maria, Av. Prof. Egas Moniz, 1600 Lisboa, Portugal

(Accepted 15 April 1988)

\begin{abstract}
SUMMARY
The investigation of an outbreak of cryptosporidiosis in a hospital day-care centre is reported. Twenty-eight $(27 \%)$ children and one member of the staff were infected. Most of the cases were symptomatic and the major presenting symptom was watery diarrhoea. Shedding of oocysts continued for a mean of 12 days after diarrhoea had subsided and most of the cases were still excreting oocysts when the first follow-up sample was examined. Intermittent shedding or a carrier state were not seen in any of the cases. Giardia intestinalis cysts were detected in 19 children, 7 of whom showing mixed infection with Cryptosporidium sp., but this association was not statistically significant. All cases recovered without specific therapy. No definite proof could be found to demonstrate the source of the outbreak or the route of transmission but some observations suggesting person-to-person transmission are discussed.
\end{abstract}

\section{INTRODUCTION}

Cryptosporidium sp. is a protozoan parasite now recognized as an important agent of gastroenteritis in immunosuppressed and immunocompetent man. The infection in humans has been considered to be a zoonosis, but Casemore \& Jackson (1984) suggested that human transmission by the faecal-oral route was probably more important, and that cryptosporidiosis should not be considered primarily as a zoonosis. The report of family outbreaks (Isaacs et al. 1985; Ribeiro \& Palmer, 1986), hospital and related infections (Baxby, Hart \& Taylor, 1983; Koch et al. 1985; Dryjanski et al. 1986), and day-care centre outbreaks (Wolfson et al. 1985; Taylor et al. 1985; Alpert et al. 1986) strongly suggest the occurrence of person-toperson transmission. We report an outbreak of cryptosporidiosis in a children's day-care centre of the main university hospital in Lisbon which occurred during the months of September and October 1987.

On 17 September 1987, Cryptosporidium sp. oocysts were identified in stool samples from two children present in the hospital day-care centre. On the next day, another case was detected. All three children were suffering from gastroenteritis. An investigation was started involving all the children and staff present in the centre. Twenty-nine cases of cryptosporidiosis were identified during a 3-week period. 


\section{MATERIALS AND METHODS}

Hospital de Santa Maria is a university hospital located in Lisbon. It has a daycare centre to serve the children of hospital staff. In September the centre was attended by 103 children. Day-care staff included 22 local people.

A case was defined as anyone, whether symptomatic or not, in whose stool Cryptosporidium sp. oocysts were identified. After detection of the first cases, samples from all the children and staff present in the centre were examined. Anyone who had diarrhoea after the first stool examination was tested a second time. Only human stool specimens were studied.

$\chi^{2}$ test with Yates correction was used to compare variables.

\section{Microbiological methods}

Initially, stool samples submitted to the laboratory were examined for Salmonella, Shigella, Campylobacter and Yersinia spp. by standard methods. Each specimen was also concentrated by a modification of the formol-ether method (Casemore, Armstrong \& Sands, 1985) and examined for helminth ova and protozoal cysts. Cryptosporidium sp. oocysts were detected on faecal smears stained by a modified Ziehl-Neelsen method (Casemore, Armstrong \& Sands, 1985) with the following further modifications : decolorization was performed with $2 \% \mathrm{H}_{2} \mathrm{SO}_{4}$ in water for $2 \mathrm{~min}$ and counterstain with $1 \%(\mathrm{w} / \mathrm{v})$ methylene blue for 2 min. Each sample was examined before and after the concentration procedure. Viral studies were not performed. After detection of the outbreak, the follow-up stool samples were examined only for protozoal cysts and for Cryptosporidium sp. oocysts after concentration by the formol-ether method.

\section{Control measures}

All the detected cases were sent home. Three to seven days after diarrhoea had subsided a second stool sample was examined and if Cryptosporidium sp. oocysts were detected, further follow-up samples were submitted with one week intervals until a negative result was found. They were readmitted to the centre only when the examination of three consecutive stool specimens obtained on different days (minimum interval of $\mathbf{2}$ days between each specimen) did not reveal the presence of Cryptosporidium sp. oocysts. Clinical and epidemiological information was collected retrospectively by interviewing the parents of the children.

\section{RESULTS}

During the investigation period, from September to October 1987, 352 stool specimens were examined. Cryptosporidium sp. oocysts were detected in 195 specimens corresponding to 28 of $103(27 \%)$ children and to one member of the staff (Fig. 1). Cysts of Giardia intestinalis, another recognized enteric pathogen, were found in 19 children. In 14 specimens both Cryptosporidium sp. oocysts and $G$. intestinalis cysts were seen, corresponding to seven cases of mixed infection. However, this association was not statistically significant $\left(\chi^{2}=0.58, P>0.2\right)$.

Age and sex distribution of the 29 cases are reported in Table 1. Twenty-seven out of the 29 cases were symptomatic and the association between Cryptosporidium 


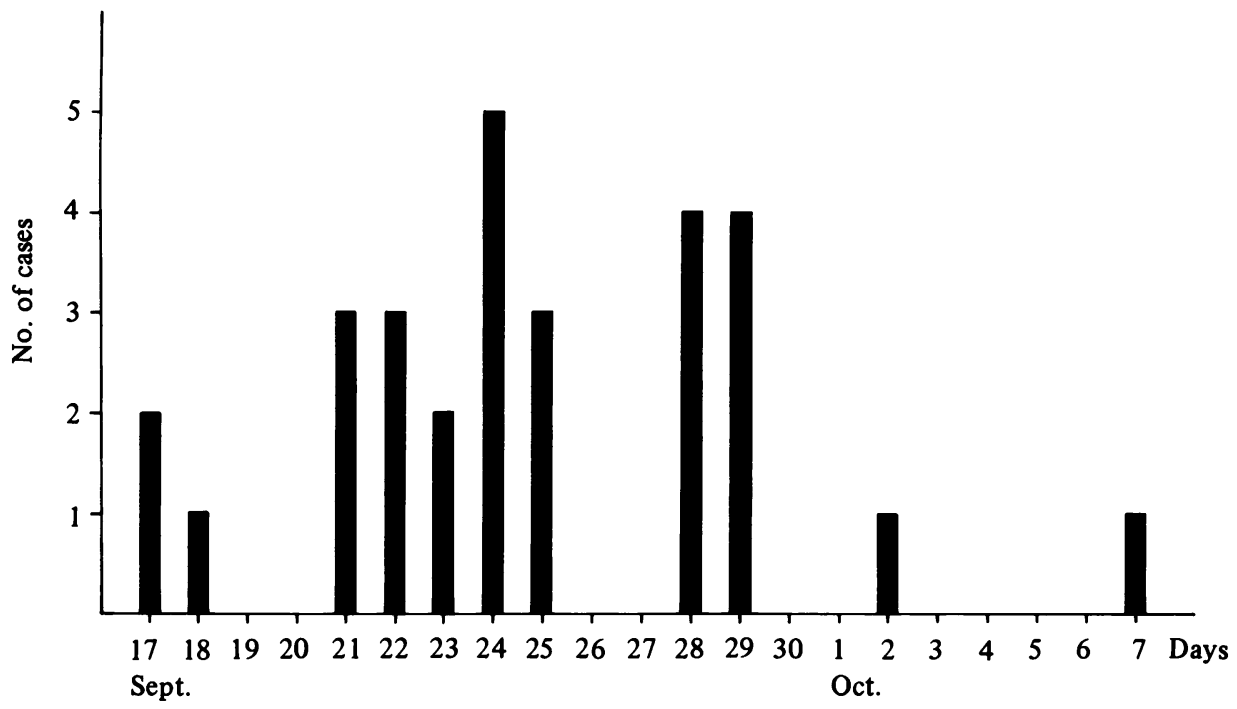

Fig. 1. Cases of cryptosporidiosis by date of first stool identification between 17 September and 7 October 1987.

Table 1. Age and sex distribution of the 29 cases of cryptosporidiosis

\begin{tabular}{crr} 
Age & \multicolumn{2}{c}{ Sex } \\
\cline { 2 - 3 } (years) & $M$ & $F$ \\
$<1$ & 2 & 1 \\
$1-2$ & 11 & 10 \\
$3-4$ & 2 & 2 \\
22 & - & 1
\end{tabular}

Table 2. Major clinical features of the 29 cases of cryptosporidiosis

Symptom
Diarrhoea
Anorexia
Lassitude
Abdominal discom
Fever $\left(\geqslant 38 \cdot 5{ }^{\circ} \mathrm{C}\right.$ )
Weight loss $\geqslant 10 \%$
Vomiting
Asymptomatic
Duration of
symptoms (days)
$1-3$
$4-7$
$8-14$
$15-21$
$>21$

No. of cases

27

22

17

13

11

8

8

2 
sp. infection and diarrhoea was statistically significant $\left(\chi^{2}=50 \cdot 26, P<0 \cdot 01\right)$. The major presenting symptom was watery diarrhoea $(27$ cases, $93 \%)$ with stool frequency varying from once a day ( 1 case) to 12 times a day (1 case) but was most commonly 3-5 (18 cases, $62 \%)$. Other major clinical features are reported in Table 2.

All cases recovered without specific therapy. Shedding of oocysts continued for a variable length of time ranging from 3-32 days with a mean duration of 12 days. After diarrhoea had subsided, 22 of the 27 symptomatic cases were still excreting oocysts when the first follow-up samples were examined.

The occurrence of diarrhoea was reported by seven household contacts. During the last 2 weeks of October, stool specimens were submitted to the laboratory by three of them. Cryptosporidium sp. oocysts were not identified in these specimens, perhaps because they were studied too late.

\section{DISCUSSION}

Since the description of cryptosporidiosis in immunocompetent children by Casemore \& Jackson (1983) many studies have confirmed Cryptosporidium sp. as a common agent of gastroenteritis. However, cryptosporidiosis appears to be generally uncommon in the Lisbon area (unpublished data). We report here the first outbreak of cryptosporidiosis occurring in a hospital day-care centre in Portugal.

The index case was probably a 17 -month-old girl who suffered from diarrhoea for a 2-day period 12 days before the detection of the outbreak. At that time, stool specimens had not been submitted to the laboratory and she did not stop attending the centre. After the onset of the outbreak, Cryptosporidium sp. oocysts could still be found in her stool specimens. No other detected case gave a history of recent diarrhoea.

No definite proof could be found to demonstrate either the source of the outbreak or the route of transmission. However, several features suggested that a common source of infection was unlikely and that person-to-person spread occurred. Although environmental microbiologic studies have not been performed, there was no evidence to implicate the water, milk or food as the route of infection. The children of the hospital paediatric wards used the same water supply and were fed from the same supply of milk and food as the children in the day-care centre but the outbreak did not involve the paediatric wards.

Contact with animals did not seem to be related to the occurrence of the infection. All the children lived in an urban community and the presence of animal pets in the household was similar for children with and without cryptosporidiosis. The pattern of onset of the disease (Fig. 1) also suggests that person-to-person transmission was more likely than a common source of infection.

In contrast with cryptosporidiosis, giardiasis is a common infection in children in the Lisbon area (Abranches, Lobo \& Silva-Pereira, 1986). Although $G$. intestinalis was identified in 19 children, it was not statistically associated with Cryptosporidium sp. $(P>0 \cdot 2)$. This association has been reported in similar outbreaks elsewhere (Taylor et al. 1985; Wolfson et al. 1985).

The length of shedding of oocysts after diarrhoea had subsided could be 
determined and the findings were similar to those of Baxby, Hart \& Blundell (1985). Intermittent shedding or a carrier state were not seen in any of the cases.

The present report supports the studies showing that Cryptosporidium sp. is one more microorganism that can be easily transmitted in day-care centres, causing outbreaks of self-limiting gastroenteritis. Person-to-person transmission, probably by the faecal-oral route especially in children seems to be an important way for the spread of cryptosporidiosis.

We wish to express our gratitude to Dr D. P. Casemore for his helpful advice and encouragement and for reviewing the manuscript.

\section{REFERENCES}

Abranches, P., Lobo, M. R. \& Silva-Pereira, M. C. D. (1986). Frequência de parasitoses intestinais observada em amostras de fezes do serviço de patologia clínica do Hospital de Egas Moniz. Boletim do Hospital Egas Moniz 3, 13-21.

Alpert, G., Bell, L. M., Kirkpatrick, C. E., Budnick, L. D., Campos, J. M., Friedman, H. M. \& Plotkin, S. A. (1986). Outbreak of cryptosporidiosis in a day-care center. Pediatrics 77, 152-157.

BaXby, D., Hart, C. A. \& Blundell, N. (1985). Shedding of oocysts by immunocompetent individuals with cryptosporidiosis. Journal of Hygiene 95, 703-709.

BaXby, D., HaRT, C. A. \& TAYlor, C. (1983). Human cryptosporidiosis: a possible cause of hospital cross infection. British Medical Journal 287, 1760-1761.

Casemore, D. P., Armstrong, M. \& Sands, R. L. (1985). Laboratory diagnosis of cryptosporidiosis. Journal of Clinical Pathology 38, 1337-1341.

Casemore, D. P. \& Jackson, F. B. (1983). Sporadic cryptosporidiosis in children. Lancet ii, 679.

CASEmore, D. P. \& JACkson, F. B. (1984). Hypothesis: cryptosporidiosis in human beings is not primarily a zoonosis. Journal of Infection 9, 153-156.

Dryjanski, J., Gold, J. W. M., Ritchie, M. T., Kurtz, R. C., Lim, S. L. \& Armstrong, D. (1986). Cryptosporidiosis - Case report in a health team worker. American Journal of Medicine 80, 751-752.

Isaacs, D., Hunt, G. H., Philips, A. D., Price, E. H., Raafat, F. \& Walker-Smith, J. A. (1985). Cryptosporidiosis in immunocompetent children. Journal of Clinical Pathology 38, 76-81.

Koch, K. L., Philips, J., Aber, R. C. \& Current, W. L. (1985). Cryptosporidiosis in hospital personnel. Evidence for person-to-person transmission. Annals of Internal Medicine 102, 593-596.

Ribeiro, C. D. \& Palmer, S. R. (1986). Family outbreak of cryptosporidiosis. British Medical Journal 292, 377.

Taylor, J. P., Perdue, J. N., Dingley, D., Gustafson, T. L., Patterson, M. \& Reed, L. A. (1985). Cryptosporidiosis outbreak in a day care center. American Journal of Diseases of Children 139, 1023-1025.

Wolfson, J. S., Richter, J. M., Waldron, M. A., Weber, D. J., McCarthy, D. M. \& Hopkins, C. C. (1985). Cryptosporidiosis in immunocompetent patients. New England Journal of Medicine 312, 1278-1282. 